DOI 10.37882/2223-2982.2021.10.15

\title{
РОЛЬ СПОРТИВНЫХ ИГР В РАЗВИТИИ ФИЗИЧЕСКОЙ ПОДГОТОВКИ ШКОЛЬНИКОВ (НА ПРИМЕРЕ ВОЛЕЙБОЛА)
}

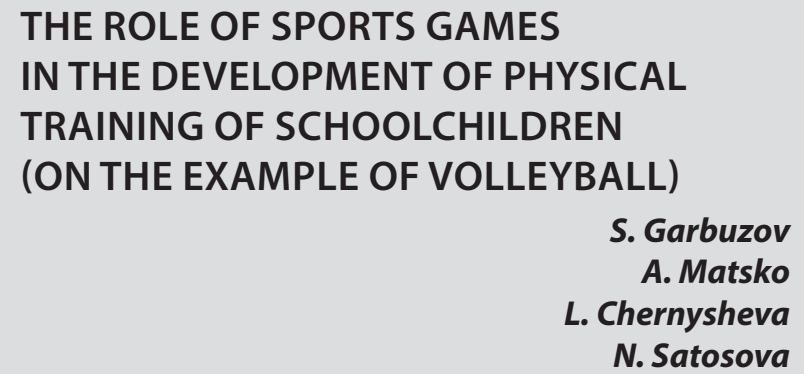

THE ROLE OF SPORTS GAMES

IN THE DEVELOPMENT OF PHYSICAL TRAINING OF SCHOOLCHILDREN

(ON THE EXAMPLE OF VOLLEYBALL)

S. Garbuzov

A. Matsko

L. Chernysheva

N. Satosova

Summary: The article analyzes the problem of physical education of schoolchildren as one of the characteristic features of modern education; the role of sport in the development of personal qualities of students of secondary educational institutions is considered; on the example of playing volleyball, the influence of sports on the physical health of a child and his functional capabilities of the body is studied.

The article also presents the results of a comprehensive study of the control and experimental groups of schoolchildren on the subject of the influence of playing volleyball on the development of their physical qualities; the conclusion is made about the high role of volleyball as a sports game in the development of physical fitness of schoolchildren.

Keywords: volleyball, physical qualities, schoolchildren, physical activity, physical qualities, training.
Гарбузов Сергей Петрович

К.п.н., доцент, Армавирский государственный педагогический университет Garbuzow.sergey2017@yandex

Мацко Андрей Иванович

К.п.н., дочент, Армавирский государственный педагогический университет andrmaz@mail.ru

Чернышева Лариса Георгиевна

К.п.н., дочент, Армавирский государственный педагогический университет

tschern@yandex.ru

Сатосова Наталья Леонидовна

К.б.н., дочент, Армавирский государственный педагогический университет

Аннотация: В статье анализируется проблема физического воспитания школьников как одна из характерных особенностей современного образования; рассматривается роль спорта в развитии личностных качеств учеников средних общеобразовательных учреждений; на примере игры в волейбол изучается влияние спорта на физическое здоровье ребенка и его функциональные возможности организма.

Также в статье представлены результаты комплексного исследования контрольной и экспериментальной групп школьников на предмет влияния игры в волейбол на развитие их физических качеств; делается вывод 0 высокой роли волейбола как спортивной игры в развитии физической подготовки школьников.

Ключевые слова: волейбол, физические качества, школьник, физическая активность, физические качества, тренировка.

скольку он облегчает процесс их социализации. Спорт и физическая активность могут предотвратить проблемы со здоровьем ребенка, в том числе чрезмерное ожирение в детстве и, конечно же, во взрослом возрасте.

Благодаря спорту и физической активности ребенок учится побеждать и принимать поражения, вести честную игру на соревнованиях и в жизни, а также развивать дружеские отношения. Период школьного возраста очень подходит для повышения осведомленности о важности физического воспитания, формирования привычки к физическим упражнениям, развития двигательных способностей учащихся.

Тогда как, по мнению С.И. Анфимовой, низкий уровень здоровья современных школьников приводит к негативным последствиям не только индивидуального, но и общего, социального значения [1].

Таким образом, необходимо знакомить детей с вли- 
янием оптимального уровня физической активности, особенно в этом возрасте. В основе физического воспитания школьников с учетом психологических аспектов личности ребенка должны лежать игровые технологии.

Одним из направлений повышения физической активности школьников может быть выбрана игра в волейбол. Многочисленные исследования доказали, что этот вид спорта важен для развития физических качеств учеников средних образовательных учебных заведений [3].

Кроме влияния на физическое здоровье ребенка, волейбол - эффективный фактор борьбы с усталостью, восстановлением функциональных возможностей организма и удовлетворением эмоциональных потребностей. Спектр эмоций довольно широк: каждый проигранный или выигранный мяч, а также удачные или неудачные действия партнеров, вызывают всплеск чувств у школьников. То есть, игра в волейбол сопровождается тренировкой эмоционально-психической сферы человека.

При этом очень важно, чтобы физические нагрузки на организм были постепенными и регулярными, были разнообразными и не вызывали перенапряжения и усталости организма студентов. При определении содержания волейбольных тренировок основным принципом является дифференцированный подход к учебному процессу, т. е. учебный материал формируется с учетом пола, физических кондиций, физического и технического уровня школьников.

Принцип постепенности в повышении требований к овладению двигательными навыками, развитию физических качеств и дозированию физических нагрузок очень важен в методике тренировок.

Процесс обучения волейболу включает в себя теоретический и практический материал. На теоретических занятиях особое внимание должно быть уделено проблемам медицинского контроля, самоконтроля и методике физического воспитания с учетом состояния здоровья школьников. Теоретические занятия также предполагают поиск, открытие и овладение теоретическими знаниями о технике волейбола как целостной системе движений.

Практические занятия включают в себя углубление знаний учащихся о выполнении приемов и практическое овладение ими на уровне двигательных способностей. Общая и специальная физическая подготовка по волейболу должна проводиться с учетом функциональных возможностей учеников. В этих видах тренировок основными факторами являются устранение функциональной недостаточности органов и систем, повышение работоспособности организма и овладение технико-так- тическими особенностями игры в волейбол.

С учетом указанных теоретических знаний было проведено исследование двух групп учащихся среднего общеобразовательного учреждения в количестве 60 человек. Цель исследования - изучить роль волейбола в развитии физических качеств школьников.

Исследование проходило в три этапа:

1-й этап: проведение первичного исследования уровня развития физических качеств школьников;

2-й этап:

- проведение занятий по волейболу с экспериментальной группой школьников;

- занятия по курсу общей физической подготовки с контрольной группой школьников.

3-й этап: повторное исследование уровня развития физических качеств школьников, в целях определения динамики исследуемых параметров.

Суть исследования: 60 учеников были разделены на две группы (по 30 человек): контрольная и экспериментальная. С участниками экспериментальной группы после реализации первого этапа эксперимента проводились регулярные (3 раза в неделю по 45 минут в течение полугода) занятия по волейболу. Для контрольной группы учеников проводились занятия по курсу общей физической подготовки учащихся средних общеобразовательных учреждений.

По результатам реализации первого этапа исследования контрольной группы были выявлены следующие данные:

Таблица 1

Результаты исследования контрольной группы

\begin{tabular}{|l|c|c|c|}
\hline \multicolumn{1}{|c|}{ Показатель } & $\begin{array}{c}\text { Высокий уро- } \\
\text { вень физиче- } \\
\text { ских качеств }\end{array}$ & $\begin{array}{c}\text { Средний уро- } \\
\text { вень физиче- } \\
\text { ских качеств }\end{array}$ & $\begin{array}{c}\text { Низкий уровень } \\
\text { физических } \\
\text { качеств }\end{array}$ \\
\hline $\begin{array}{l}\text { Количество } \\
\text { детей, ед. }\end{array}$ & 4 & 19 & 7 \\
\hline $\begin{array}{l}\text { Доля детей от } \\
\text { общего количе- } \\
\text { ства, } \%\end{array}$ & 13,3 & 63,3 & 23,4 \\
\hline
\end{tabular}

Исследование контрольной группы показало, что большинство детей имеют средний уровень физических качеств (19 детей из 30; 63,3\%). Кроме того, 7 детей из исследуемых контрольной группы показали низкий уровень физических качеств (23,4 \%). И всего лишь 4 человека (13,3 \%) от исследуемых детей контрольной группы имеют высокие показатели физического развития.

Далее было проведено исследование физических качеств экспериментальной группы. 
По результатам реализации первого этапа исследования экспериментальной группы были выявлены следующие данные:

Таблица 2.

Результаты исследования экспериментальной группы

\begin{tabular}{|l|c|c|c|}
\hline \multicolumn{1}{|c|}{ Показатель } & $\begin{array}{c}\text { Высокий уро- } \\
\text { вень физиче- } \\
\text { ских качеств }\end{array}$ & $\begin{array}{c}\text { Средний уро- } \\
\text { вень физиче- } \\
\text { ских качеств }\end{array}$ & $\begin{array}{c}\text { Низкий уровень } \\
\text { физических } \\
\text { качеств }\end{array}$ \\
\hline $\begin{array}{l}\text { Количество } \\
\text { детей, ед. }\end{array}$ & 3 & 18 & 9 \\
\hline $\begin{array}{l}\text { Доля детей от } \\
\text { общего количе- } \\
\text { ства, } \%\end{array}$ & 10 & 60 & 30 \\
\hline
\end{tabular}

Исследование экспериментальной группы показало, что так же как и в контрольной группе, большинство детей имеют средний уровень физических качеств (18 детей из 30; 60\%). Среди исследуемых экспериментальной группы 9 детей показали низкий уровень физических качеств (30 \%). И всего лишь 3 человека (10\%) от исследуемых детей экспериментальной группы имеют высокие показатели физического развития.

Графически результаты первого этапа исследования экспериментальной и контрольной группы представлены на рисунке 1.

Проведенный на первом этапе исследования анализ показал, что уровень развития физических качеств школьников контрольной и экспериментальной группы примерно одинаковый. Это позволяет утверждать о наличии одинаковой характеристики первоначальных физических характеристик учеников для определения более точной результативности влияния спортивных игр на развитие их физических качеств с учетом соблюдения одного из основных правил экспериментирования принципа сопоставимости.

Следует указать, что ученики обеих групп находились в хорошем общем физическом состоянии и были надлежащим образом ознакомлены со всеми экспериментальными процедурами.

Далее, на втором этапе исследования для учеников экспериментальной группы проводились занятия по волейболу (3 раза в неделю по 45 минут в течение полугода).

В состав методики тренировок входили:

1. теоретические занятия по методике игры в волейбол;

2. игры на развитие прыгучести, ловкости, силы и скорости - важных физических качеств;

3. игра в волейбол.

Выбор составных элементов методики тренировок обоснован тем, что в волейболе как игровом виде спорта делается акцент на взрывных движениях, таких как прыжки, удары и блокирование. В дополнение к техническим и тактическим навыкам (теоретические занятия по методике игры в волейбол), утверждается, что мышечная сила и мощь являются наиболее важными факторами, способствующими успешному обучению игры в волейбол.

Акцент в рамках предлагаемой методики делается на игровые технологии - игры, способствующие развитию физических качеств учащихся.

Как верно указывает В.Б. Болдырева, подвижная игра - это воспитательное и оздоровительное средство социализации, способное интенсифицировать образо-

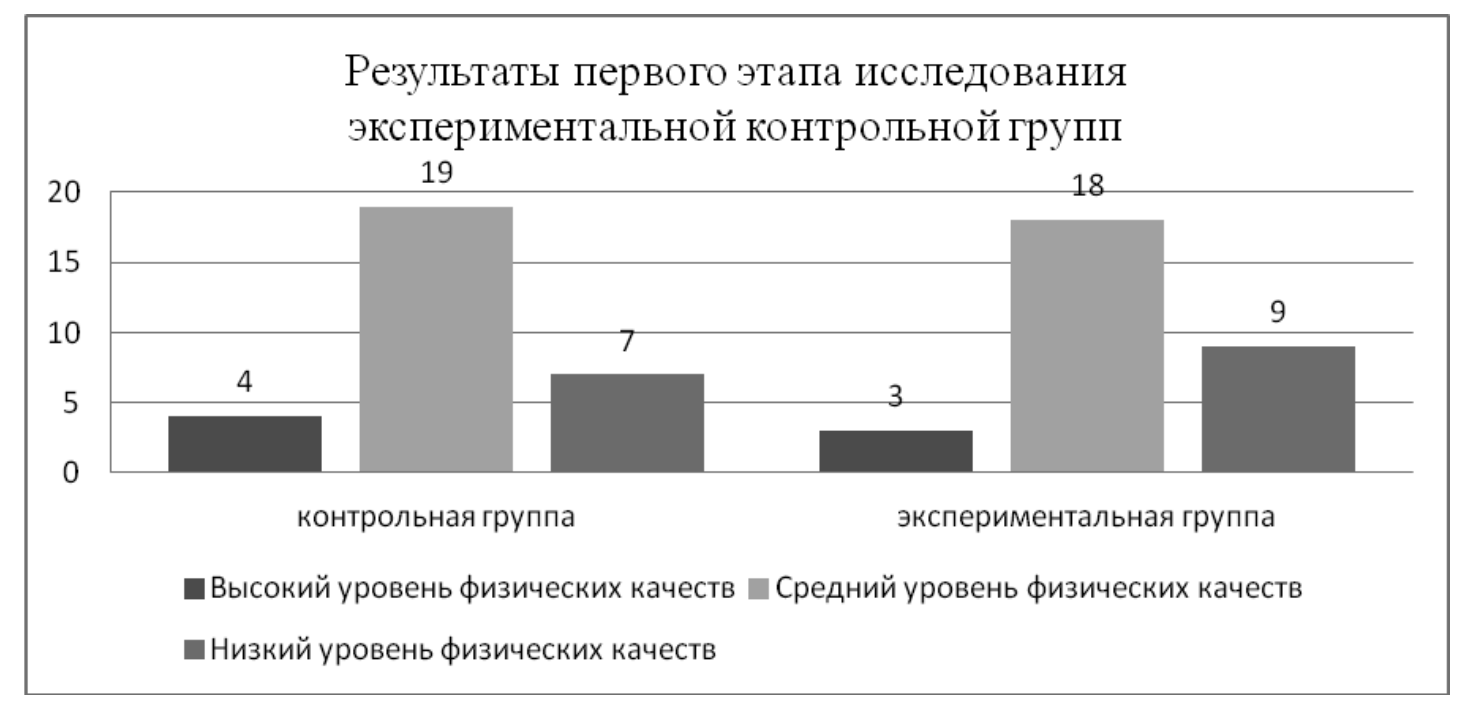

Рис. 1. Графические результаты первого этапа исследования 
вательный процесс, обеспечить мотивационную основу для формирования диалектической взаимосвязи физических и духовных качеств и самореализации личности [2].

По результатам третьего этапа исследования контрольной группы были выявлены следующие данные:

Таблица 3.

Результаты повторного исследования контрольной группы

\begin{tabular}{|l|c|c|c|}
\hline \multicolumn{1}{|l|}{ Показатель } & $\begin{array}{c}\text { Высокий уро- } \\
\text { вень физиче- } \\
\text { ских качеств }\end{array}$ & $\begin{array}{c}\text { Средний уро- } \\
\text { вень физиче- } \\
\text { ских качеств }\end{array}$ & $\begin{array}{c}\text { Низкий уровень } \\
\text { физических } \\
\text { качеств }\end{array}$ \\
\hline $\begin{array}{l}\text { Количество } \\
\text { детей, ед. }\end{array}$ & 4 & 21 & 5 \\
\hline $\begin{array}{l}\text { Доля детей от } \\
\text { общего количе- } \\
\text { ства, } \%\end{array}$ & 13,3 & 70 & 16,7 \\
\hline
\end{tabular}

Повторное исследование контрольной группы показало, что показатели развития физических качеств учеников остались без изменений. По-прежнему большинство детей имеют средний уровень физических качеств (21 ребенок из 30; 70\%). Кроме того, 5 детей из исследуемых контрольной группы показали низкий уровень физических качеств (16,7%). И всего лишь 4 человека (13,3 \%) от исследуемых детей контрольной группы имеют высокие показатели физического развития.

Далее было проведено повторное исследование физических качеств экспериментальной группы.

По результатам реализации третьего этапа исследования экспериментальной группы были выявлены следующие данные:
Таблица 4.

Результаты исследования экспериментальной группы

\begin{tabular}{|l|c|c|c|}
\hline \multicolumn{1}{|c|}{ Показатель } & $\begin{array}{c}\text { Высокий уро- } \\
\text { вень физиче- } \\
\text { ских качеств }\end{array}$ & $\begin{array}{c}\text { Средний уро- } \\
\text { вень физиче- } \\
\text { ских качеств }\end{array}$ & $\begin{array}{c}\text { Низкий уровень } \\
\text { физических } \\
\text { качеств }\end{array}$ \\
\hline $\begin{array}{l}\text { Количество } \\
\text { детей, ед. }\end{array}$ & 26 & 3 & 1 \\
\hline $\begin{array}{l}\text { Доля детей от } \\
\text { общего количе- } \\
\text { ства, } \%\end{array}$ & 87 & 10 & 3 \\
\hline
\end{tabular}

Повторное исследование экспериментальной группы показало, что большинство детей приобрели высокий уровень физических качеств (26 детей из 30; 87\%). Средний уровень физических качеств выявлен у трех детей из исследуемой экспериментальной группы (10 \%). И всего лишь у одного человека (3 \%) от исследуемых детей физические качества остались на низком уровне развития.

Графически результаты третьего этапа исследования экспериментальной и контрольной группы представлены на рисунке 2.

Проведенный на третьем этапе исследования анализ показал, что уровень развития физических качеств школьников экспериментальной группы вырос по сравнению с учениками из контрольной группы исследования.

На рисунке 3 представлена динамика изменения уровня физических качеств спортсменов контрольной и экспериментальной групп.

Таким образом, в ходе проведенного исследования было доказано, что волейбол как вид спортивной игры,

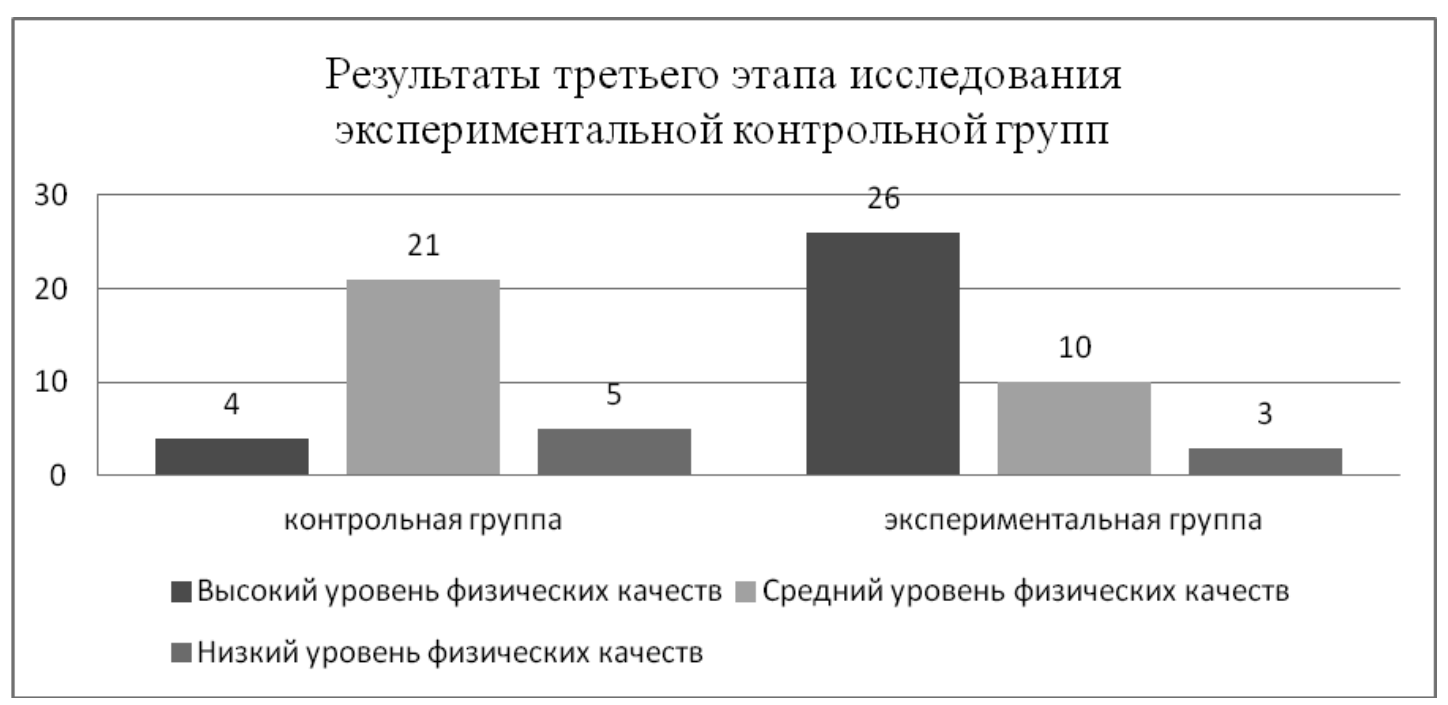

Рис. 2. Графические результаты третьего этапа исследования 


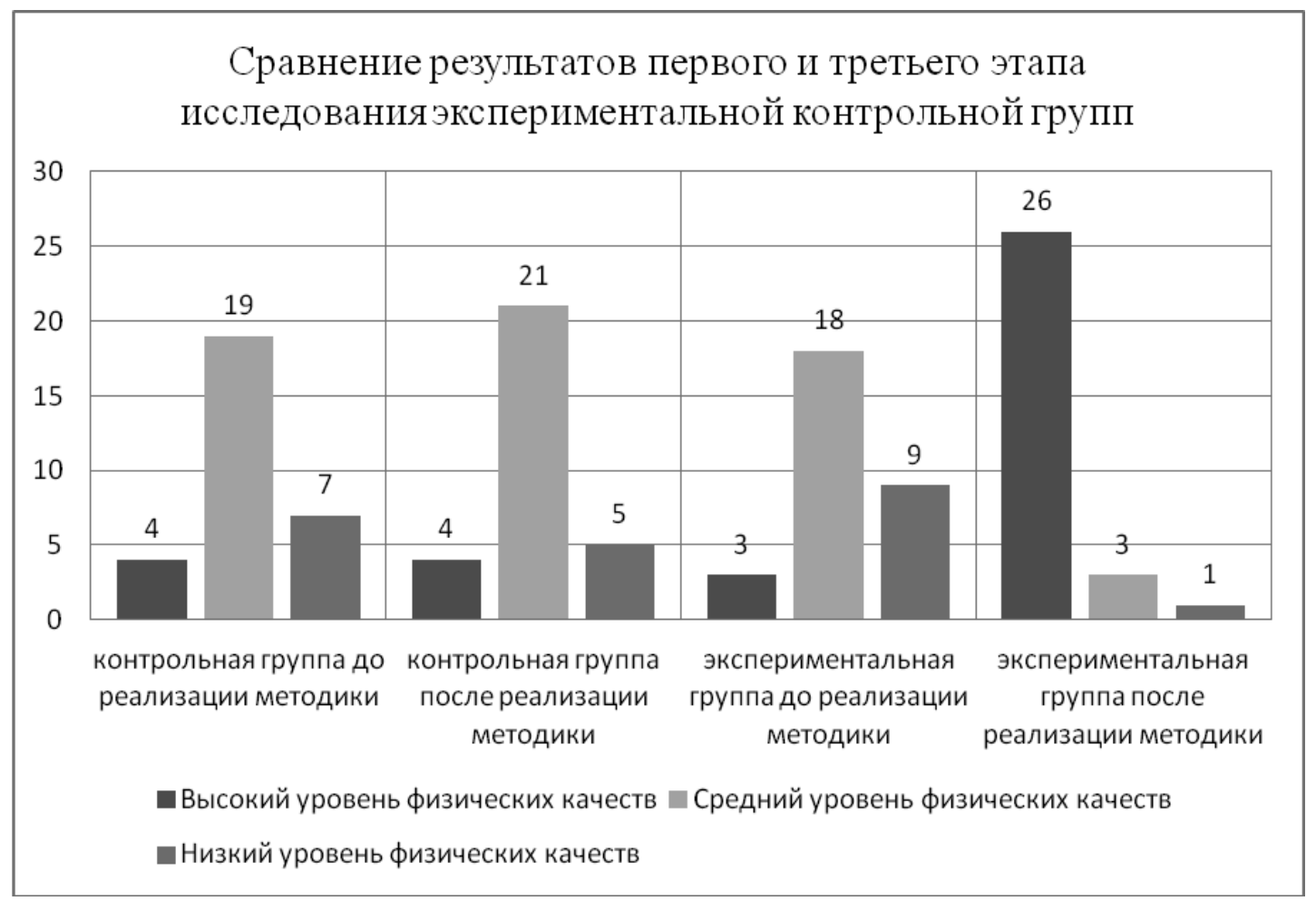

Рис. 3. Графически результаты третьего этапа исследования

оказывает большое значение на развитие физических качеств ребенка. Применение методики обучения волейболу с применением игровых технологий (подвижных игр) способствует развитию прыгучести, ловкости, силы и скорости - важных физических качеств у школьников.

Улучшение физического развития детей является самым важным вкладом спорта. Благодаря своему об- ширному охвату, беспрецедентной популярности и фундаменту позитивных ценностей, спорт, безусловно, является одной из величайших вещей, когда-либо созданных человеком. Это также мощный инструмент, который разрушает все барьеры и помогает нам чувствовать себя хорошо как физически, так и морально. Спорт весьма полезен для детей: занимаясь спортом, дети развивают физические навыки.

\section{ЛИТЕРАТУРА}

1. Анфимова С.И. Актуальность проблемы физического здоровья современных школьников / Здоровье, физическая культура и спорт в высшей школе: опыт, проблемы и перспективы. 2018. С. 52-57.

2. Болдырева В.Б. Подвижные игры в физическом воспитании молодежи / Вестник Тамбовского университета. Серия: Гуманитарные науки. 2016. С. 98-102.

3. Одинцов А.Н. Занятия волейболом как средство сохранения и укрепления здоровья обучающихся // Молодой ученый. 2016. № 17.1 (121.1). С. 31 -37. 